\title{
¿MIGRANTES "VULNERABLES"? POLÍTICAS DE MIGRACIÓN Y DERECHO A LA SALUD EN ARGENTINA ${ }^{1}$
}

\author{
María Graciela de ORTÚZAR²
}

RESUMEN: A partir del aumento de la migración en Argentina se hace necesario criticar el uso de "migrantes vulnerables" como categoría estática. Nuestro objetivo, en el estudio de la intersección de políticas internacionales y nacionales, es mostrar -a través de un concepto relacional de vulnerabilidad- cómo (I) el uso instrumental de éste concepto responde (II) a un modelo de seguridad y control en migraciones (Decreto de Necesidad y Urgencia -en adelante DNU- 70/2017, ARGENTINA, 2017), contrario a la Ley de Migraciones 25.871/2003 (ARGENTINA, 2010b) y a nuestra Constitución Nacional (CN). Éste nuevo modelo se sustenta en creencias xenófobas que habilitan (III) políticas sanitarias privatistas (Decreto de Necesidad y Urgencia -DNU- 908/2016; ARGENTINA, 2016) en el marco encubierto de la restricción del acceso a la salud al migrante ("cobertura universal de la salud"). La metodología elegida consiste en el análisis ético y político de las citadas normativas que llevaron al giro neoconservador en políticas migratorias; con la consecuente profundización de la "vulnerabilidad social" de migrantes, y a la privatización de la salud en Argentina.

PALABRAS CLAVE: vulnerabilidad; migraciones; securitización de políticas; derecho a la salud; derechos humanos.

\footnotetext{
1 Este artículo fue realizado en el marco del proyecto de investigación "El derecho humano a la salud de migrantes regionales en Argentina”, 2019-2020, CONICET; PIP “ Derechos humanos, género y diálogo intercultural en salud pública", 2021-2022, CONICET; y "Proyecto de Vinculación de la Red de Derechos Humanos RIOSP, Derechos humanos, migración y asilo, CONICET, S T 5148, 2021ss. Asimismo, forma parte del Proyecto Grupal transdisciplinario de la Universidad Nacional de La Plata (Facultad de Ciencias Jurídicas y Sociales y Facultad de Humanidades y Ciencias de la Educación), Código 11/H866, 2018-2021, dirigido por mi persona. Agradezco el apoyo institucional y financiamiento recibido. Agradezco también la ayuda de Jessica Kaufman en la traducción al portugués del resumen.

2 a) Doctora en Filosofía y Profesora Adjunta de Seminarios de Ética Aplicada, FAHCE Universidad Nacional de La Plata, La Plata - Argentina. b) Investigadora Independiente Consejo Nacional de Investigaciones Científicas y Tecnológicas (CONICET), Buenos Aires - Argentina.. c) Profesora Adjunta Ordinaria de Ética.Universidad Nacional de la Patagonia Austral, Santa Cruz - Argentina. ORCID: https://orcid.org/0000-0002-4566-4535. mariagracieladeortuzar@gmail.com.
} 


\title{
"VULNERABLE" MIGRANTS? MIGRATION POLICIES AND THE RIGHT TO HEALTH IN ARGENTINA
}

\begin{abstract}
Due to the increase in migration in Argentina, it is necessary to criticize the use of the concept of "vulnerability" as a static category applied to migrants. Our objective is to show, from (I) a relational concept of vulnerability, how its use responds; (II) to a model of migration securitization (Decree of Necessity and Urgency-DNU-70/2017, ARGENTINA, 2017); to xenophobic prejudices as basis for the unjustified and unconstitutional imposition of the aforementioned DNU; (III) covert changes directed at privatized health policies (DNU 908/2016; ARGENTINA, 2019), deepened by the irregular situation of the migrant. The chosen methodology consists of an ethical and political analysis of the aforementioned regulations that led to the neoconservative turn of migration policies and to the advance in the privatization of the right to health in Argentina.
\end{abstract}

KEYWORDS: vulnerability; migrant; migration policies; right to health; human right.

\section{MIGRANTES "VULNERÁVEIS"? POLITICAS DE MIGRAÇÃO E DIREITO À SAÚDE NA ARGENTINA}

RESUMO: Em função do aumento da migração na Argentina, torna-se necessário criticar o uso do conceito de "vulnerabilidade" como uma categoria estática aplicada a migrantes. Nosso objetivo consiste em mostrar, a partir de (I) um conceito relacional de vulnerabilidade, como o uso dele responde (II) a um modelo de securitização de migraçóes (Decreto de Necessidade e Urgência-DNU-70/2017, ARGENTINA, 2017) a preconceitos xenófobos como base para a imposição injustificada e inconstitucional dos mencionados DNU; (III) a mudanças encobertas direcionadas a politicas de saúde privatizadas (DNU 908/2016; ARGENTINA, 2016), aprofundadas pela situação irregular do migrante. A metodologia escolbida consiste na análise ética e politica das citadas regulamentaçôes que levaram ao giro neoconservador das políticas migratórias e ao avanço na privatização do direito à saúde na Argentina.

PALAVRAS-CHAVE: vulnerabilidade; migrante; politicas migratórias; direito à saúde; direito humano. 


\section{Introducción}

El presente trabajo trata del modo en que "la vulnerabilidad" y las políticas públicas de migraciones se intersectan en distintos ámbitos (internacional y nacional -Argentina-), generando mayores desigualdades para el mismo sujeto migrante, en clara desventaja con las/los nacionales, ante los recientes efectos del giro hacia políticas de seguridad en migraciones. La importancia de cómo definamos la vulnerabilidad y su vinculación con los paradigmas de políticas migratorias en pugna, incidirá en la protección de derechos humanos -DDHH(paradigma de DDHH); o, por el contrario, facilitará la implementación de políticas de control y seguridad (Paradigma regulatorio de seguridad), encubriendo la privatización de bienes públicos, como ocurre con el derecho a la salud.

Los migrantes, aquellas personas que han debido dejar su país de origen y residen en un país diferente, son considerados por la Organización Internacional para las Migraciones -OIM- (OIM, 2021) como personas particularmente "vulnerables". En este grupo se incluye a los indocumentados que se desplazan de manera irregular, los menores, las mujeres embarazadas, las personas enfermas, las víctimas de violencia y las víctimas de tráfico de personas. Pero, ¿qué significa, a nivel político, considerar a los migrantes como grupos vulnerables?; ¿qué entendemos por vulnerabilidad?; ¡es la vulnerabilidad un concepto unívoco?; ¿qué usos políticos posee la categoría de vulnerabilidad aplicada a migrantes?

En una primera aproximación general, observamos que el concepto de vulnerabilidad es, en sí mismo, un concepto ambiguo (demasiado amplio o demasiado estrecho; fijo o dinámico; genera dependencia o promueve la autodeterminación). De acuerdo a la Real Academia Española (VULNERABLE, 2019) una persona vulnerable es "aquella que puede ser herida o recibir una lesión física o moral”. En filosofía, la vulnerabilidad es condición humana inherente a su existencia, en su finitud y fragilidad, de manera tal que no puede ser superada o eliminada (O’NEILL, 1996). Si bien este concepto es demasiado amplio, Neves (2009) sostiene que al reconocerse como vulnerables, las personas comprenden la vulnerabilidad del otro, así como la necesidad del cuidado, de la responsabilidad y de la solidaridad, y la no explotación de esa condición por parte de otros. Pero, si definimos la vulnerabilidad en sentido estrecho, apelando a las características atribuidas a grupos (mujeres, ancianos, niños, discapacitados, comunidades étnicas, entre otros), esto nos lleva a considerar que los rasgos de estos grupos son fijos y estáticos, condenándolos a no cambiar y estigmatizando a los mismos. Un aporte interesante al tema, desde las ciencias sociales, es el concepto de "vulnerabilidad social". El mismo está compuesto por dos planos: 
uno referido al plano estructural (hogares/infraestructura/ movilidad); y otro referido a sus consecuencias en la esfera subjetiva, esto es, a los sentimientos de indefensión, incertidumbre e inseguridad (KAZTMAN, 1999; FILGUEIRA, 2001). La ventaja de esta categoría de vulnerabilidad social y sus dos planos es que la misma habilitaría un estudio dinámico (disposicional-contextualista), no encasillando a los grupos en categorías estáticas (MORZILLI; LEMMI, 2020).

El análisis específico del concepto de "migrantes vulnerables" merece especial atención en las normativas de migraciones, debido a que el mismo posee usos e implicancias opuestos en la formulación de políticas públicas. A modo de ejemplo, la vulnerabilidad de migrantes para el paradigma de derechos humanos exige reconocer que los derechos del otro deben ser protegidos por el Estado

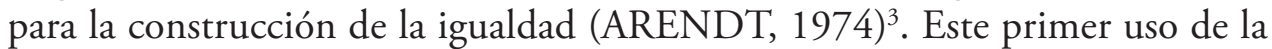
vulnerabilidad se centra en la responsabilidad del Estado, de los ciudadanos y de las organizaciones sociales. Paradójicamente, el concepto de vulnerabilidad es utilizado para identificar grupos migrantes a los cuáles se aplican políticas de control y seguridad, a partir de la reciente securitización de políticas migratorias, ejemplificado en la Argentina con el viraje hacia políticas neoconservadoras en migraciones (ARGENTINA, 2017). En el centro de estos debates sociopolíticos actuales sobre migraciones, se encuentra la disputa teórica y la tensión actual entre ambos paradigmas. Mi hipótesis, al respecto, es que dichas políticas de control, centradas en la supuesta "protección efectiva de migrantes vulnerables”; no sólo profundizan la vulnerabilidad social de los que dicen proteger, estigmatizándolos; sino que también ponen en peligro la protección de bienes públicos, como lo es la atención de la salud (derecho a la salud), encubriendo su privatización bajo el discurso de la "cobertura universal de la salud".

El objetivo del presente trabajo es el análisis de la vulnerabilidad de migrantes en la intersección de políticas internacionales y nacionales (Argentina), mostrando, a través de (I) un concepto relacional de vulnerabilidad, cómo el uso instrumental de éste concepto responde (II) a un modelo de securitización de políticas migratorias (ARGENTINA, 2017), contrario a la Ley de Migraciones Nro. 25.871/2003 (ARGENTINA, 2010b) y a nuestra Constitución Nacional $(\mathrm{CN})$, e impulsado por creencias xenófobas (migrante como delincuente) que llevaron, en el campo de la salud, (III) a promover políticas sanitarias privatistas (DNU 908/2016; ARGENTINA, 2019 -cobro de seguros a migrante) al mismo tiempo que se aplica la "cobertura universal de la salud". La metodología elegida

\footnotetext{
3 Según Hannah Arendt, en Los orígenes del totalitarismo, la autora señala el error cometido por los estados-nación de Europa al no otorgar derechos humanos a los no nacionales, remarcando que estos derechos sólo pueden ser garantizados dentro del contexto del estado-nación. (Véase al respecto Arendt [1974, cap. 9] y Benhabib [2006]).
} 
se basa en el análisis ético y político de las normativas citadas que llevaron al giro neoconservador en políticas de migraciones, con la consecuente profundización de la vulnerabilidad social de migrantes y de la privatización de la salud en Argentina.

\section{Análisis filosófico crítico del concepto de vulnerabilidad aplicado en políticas migratorias}

\section{I.1. Paradigma de Derechos Humanos -DDHH-: los migrantes no son intrínsecamente vulnerables}

De acuerdo al Informe del Alto Comisionado de las Naciones Unidas para los Derechos Humanos (UN HUMAN RIGHTS COUNCIL, 2017), los migrantes vulnerables son los migrantes que no pueden gozar de manera efectiva de sus derechos humanos, que corren un mayor riesgo de sufrir violaciones y abusos, y que, por consiguiente, tienen derecho a reclamar una mayor protección a los garantes de derechos. Dicha Organización señala, muy oportunamente, que:

[...] los migrantes no son intrínsecamente vulnerables ni carecen de [resiliencia] y capacidad de actuación. Por el contrario, la vulnerabilidad ante las violaciones de sus derechos humanos es el resultado de múltiples formas de discriminación interrelacionadas, de la desigualdad y de dinámicas estructurales y sociales que imponen límites y desequilibrios en los niveles de poder y de disfrute de los derechos (UN HUMAN RIGHTS COUNCIL, 2017, p.13, nuestra traducción).

En relación a los derechos humanos, la Organización Mundial de la Salud (OMS, 2007) señala la importancia de garantizar a todos los migrantes un derecho humano básico, como lo es el derecho a la salud, considerando a la misma migración como un determinante global de la salud (ALTAMIRANO RÚA, 2014). Cito:

Las personas que acaban de migrar a menudo se ven enfrentadas a una situación de pobreza y marginación y tienen escaso acceso a prestaciones sociales y servicios de salud, sobre todo en los primeros tiempos de la inserción en un nuevo entorno (ya sea dentro o fuera del país de origen o retorno). Por su parte, los trabajadores migratorios estacionales y poco 
especializados suelen concentrarse en sectores y ocupaciones con un alto nivel de riesgos de salud ocupacional. Los familiares, incluidos los niños, a veces desempeńan la misma actividad y, por lo tanto, pueden verse expuestos a esos riesgos. Las víctimas de la trata de personas, sobre todo las mujeres y los niños, son particularmente vulnerables a los problemas de salud y tienen más probabilidades que otros grupos de población de padecer enfermedades transmisibles y no transmisibles, así como problemas de salud mental. La migración, cuando está desencadenada por desastres o conflictos, situaciones de inseguridad alimentaria, enfermedades o cambios climáticos y otros peligros medioambientales, guarda una estrecha relación con la destrucción de los medios de subsistencia y a menudo con problemas de los sistemas de salud. Esos determinantes económicos, políticos, sociales y ambientales de la salud de los migrantes ponen de relieve la importancia de establecer políticas intersectoriales, incluidas políticas destinadas a reducir el riesgo de desastres, que puedan tener efectos tanto en el proceso migratorio como en sus consecuencias más graves para la salud. (OMS, 2007, p..2).

La definición precedente de vulnerabilidad de la Organización de las Naciones Unidas- ONU-, como la preocupación por la equidad en salud de los migrantes de la Organización Mundial de la Salud -OMS del 2007-, se insertan en el paradigma de derechos humanos, desde donde la preocupación internacional por el derecho a la migración y el derecho a la salud de los migrantes entran en la esfera de la igualdad/justicia, bajo la forma de políticas integrales e intersectoriales, no pudiéndose negar la asistencia sanitaria gratuita a las personas migrantes.

En los últimos años el uso que se hace de la vulnerabilidad, en las normativas y políticas internacionales en migraciones, dista mucho del concepto de "vulnerabilidad" enmarcada en el paradigma de derechos humanos. De la misma manera, el reconocimiento del derecho a la salud de migrantes es cuestionado desde niveles provinciales y nacionales. Estudiar las implicancias del cambio en el citado concepto nos permitirá comprender las líneas políticas que emanan a nivel internacional y nacional en migraciones, determinando: a) si el mismo contribuye a proteger a los migrantes; o b) si se realiza sólo un uso instrumental del concepto para impulsar políticas de control, seguridad y privatización en torno a salud y migraciones. 


\section{I.2. Políticas regulatorias de seguridad y uso instrumental de vulnerabilidad para "migración segura"}

De acuerdo a la Agencia de la ONU para los Refugiados, se promueve una migración mundial segura, ordenada y regular. Cito:

Los 193 Estados Miembros de las Naciones Unidas se comprometen a considerar la posibilidad de elaborar principios rectores no vinculantes y directrices voluntarias sobre el trato de los migrantes en situaciones de vulnerabilidad, mediante un proceso dirigido por los Estados.Además se comprometen a iniciar un proceso de negociaciones intergubernamentales que culminarán con la aprobación de un pacto mundial para la migración segura, ordenada y regular "que podría incluir [...] elementos [...] para la protección efectiva [...] de los migrantes en situaciones de vulnerabilidad (ACNUR, 2017, el subrayado es mío).

Como podemos observar en el párrafo anterior, se establece una vinculación entre migrantes en situaciones de vulnerabilidad y el pacto mundial intergubernamental para la migración segura, ordenada y regular; conceptos claves que definirán las políticas internacionales de migración. Este paradigma favorece el movimiento internacional de capitales y mercancías, pero restringe y controla el movimiento de personas entre fronteras. La seguridad aquí se encuentra en el centro de dicha política, no la protección del migrante.

Bajo este marco regulatorio, se distinguen tres tipos de vulnerabilidad de migrantes:

1. "Vulnerabilidad situacional, se refiere a las circunstancias durante la ruta o en los países de destino que ponen a los migrantes en riesgo". ${ }^{4}$

2. "Vulnerabilidad individual", tiene que ver con características o circunstancias individuales que ponen a una persona en un riesgo particular (niños, adultos mayores; personas con discapacidades y/o necesidades

\footnotetext{
4 Esto sucede con frecuencia cuando la migración se realiza por vías irregulares, provocando que las personas queden expuestas a explotación y abuso por parte de traficantes, tratantes, reclutadores y funcionarios corruptos; así como el riesgo de muerte a bordo de barcos no aptos para la navegación o durante el paso por desiertos peligrosos $\mathrm{u}$ otros cruces terrestres. Los riesgos pueden exacerbarse por falta de documentación legal, ausencia de apoyo de la familia o de la comunidad, conocimiento limitado del idioma local, o discriminación.
} 
médicas; víctimas o supervivientes de trata que no entran en el ámbito de la definición de refugiado).

3. "Vulnerabilidad vinculada con las condiciones en el país de origen de un migrante que preceden a su partida": privación socioeconómica o falta de acceso a los derechos humanos fundamentales (refugiados)" (UN HUMAN RIGHTS COUNCIL, 2017, p. 5).

Si bien podría considerarse que se señalan factores que hacen a la vulnerabilidad social -como serían las condiciones del migrante en el país de origen o en las circunstancias de la ruta-; al acentuarse la ilegalidad y los riesgos referidos a grupos fijos (mujeres, niños, ancianos, entre otros), ignorando a los responsables y/o a las políticas públicas que deberían revertir estas condiciones; no se comprende cómo "la migración segura, ordenada y regular... permitiría la protección efectiva de migrantes en situaciones de vulnerabilidad" (ACNUR, 2017). Esto es, la enumeración de características específicas referidas a personas y/o grupos tornaría fuertemente estigmatizador al concepto de vulnerabilidad, impidiendo el cambio, y no permitiendo empoderar a estos grupos para salvaguardar su dignidad, integridad y derechos humanos. Dicha definición desconoce las múltiples formas de discriminación interrelacionadas, de la desigualdad y de dinámicas estructurales y sociales que imponen desequilibrios de poder y goce de los derechos (UN HUMAN RIGHTS COUNCIL, 2017); como también desconoce las relaciones institucionales e históricas que hicieron posible el sometimiento de personas, grupos, pueblos y naciones enteras; creando relaciones de colonialismo, dominación y dependencia bajo una misma lógica monocultural (QUIJANO, 2000, 2005; MIGNOLO, 2007, FREIRE; FREIRE, 2014). El uso instrumental de vulnerabilidad sólo se limita a identificar grupos generalizados -migrantes vulnerables- para reglamentar sus vidas a través de políticas de seguridad y control, despreocupándose de sus necesidades, derechos y de su bienestar humano.

\section{I.3. Propuesta de una categoría relacional de vulnerabilidad para aplicar a migrantes}

Necesitamos de una categoría de vulnerabilidad que reconozca responsabilidades en la protección de derechos básicos, recuperando el sentido dinámico, histórico, crítico y relacional de la vulnerabilidad para el empoderamiento de las personas y grupos. Al respecto, adherimos a la definición propuesta por Goodin (1985, p. 112): "la vulnerabilidad no es un estado azaroso, implica una 
relación asimétrica de poder. Supone la existencia de un agente capaz de ejercer una elección efectiva tanto para causar, prevenir o evitar la amenaza del dańo". La citada definición nos permite ampliar el análisis a las relaciones asimétricas de poder que se dan entre Estados a nivel internacional, y, la relación asimétrica de poder entre el migrante y el Estado a nivel nacional.

El objetivo de este concepto de vulnerabilidad relacional es proteger contra toda clase de daño (engaño, mentira, tortura, muerte, violación, entre otros) a los migrantes. Aquí es preciso entender que el daño es evitable y previsible, pudiéndose anticipar y actuar a través de políticas públicas para revertirlo. Por ejemplo, si existe un responsable por el aumento de migraciones forzosas -daño generado por razones económicas, ambientales o políticas que obligan a las personas a migrar-; éste daño debe ser compensado a través de políticas inclusivas basadas en modelos de migraciones inspirados en derechos humanos. Al respecto, las políticas de DDHH permiten prever riesgos y actuar sobre la vulneración de derechos de migrantes; mientras que las políticas securitistas, al no prever el daño, anticiparlo o revertirlo, contribuyen aún más a la vulneración de los derechos de las personas migrantes.

En este punto distinguimos entre personas vulnerables y derechos vulnerados. De acuerdo a Schram (2006) y Kottow (2008) todos somos vulnerables, en tanto la fragilidad es constitutiva de la naturaleza humana. Por ello, los derechos humanos protegen la vulnerabilidad humana resguardando bienes básicos y protegiendo el acceso igualitario a los mismos para impedir el daño o lesión de la persona. Cuando este daño se produce, existen derechos vulnerados que deben atenderse por las instituciones sociales para compensar y empoderar a los desfavorecidos. Requiere de parte del Estado acciones afirmativas y reparadoras que interfieran en la autonomía, la integridad y la dignidad de los vulnerados.

Seguidamente pasaremos a analizar cómo el reciente DNU 70/2017 (ARGENTINA, 2017) llevó a la profundización de derechos vulnerados de migrantes; significando un claro retroceso de las conquistas alcanzadas, a partir de la Ley Nro. 25.871/2003 de Argentina (2010b), en derechos humanos en migraciones.

\section{El retroceso en políticas de migratorias a partir del DNU 70/2017 en Argentina}

El camino de conquistas de derechos humanos en políticas migratorias en Argentina se encuentra signado por avances y retrocesos. Nuestra Constitución Nacional (GELLI, 2005) alienta positivamente la inmigración, invitando a 
las personas que habitan el mundo -sin importar su origen- a habitar el suelo argentino. El Preámbulo de la Constitución Nacional Argentina de 1853 (ARGENTINA, 1994) establece:

Nos, los representantes del pueblo de la Nación Argentina, reunidos en Congreso General Constituyente por voluntad y elección de las provincias que la componen, en cumplimiento de pactos preexistentes, con el objeto de constituir la unión nacional, afianzar la justicia, consolidar la paz interior, proveer a la defensa común, promover el bienestar general, y asegurar los beneficios de la libertad, para nosotros, para nuestra posteridad, y para todos los hombres del mundo que quieran habitar en el suelo argentino: invocando la protección de Dios, fuente de toda razón y justicia: ordenamos, decretamos y establecemos esta Constitución, para la Nación Argentina.

En su artículo 20 expresa: "Los extranjeros gozan en el territorio de la Nación de todos los derechos civiles del ciudadano; pueden ejercer su industria, comercio y profesión y no están obligados a admitir la ciudadanía, ni a pagar contribuciones forzosas extraordinarias" (ARGENTINA, 1994).

En esta misma línea, la Ley de Migraciones, Nro. 25871 (ARGENTINA, 2010b), aprobada en diciembre de 2003 y reglamentada en el 2010 a través de un proceso de consulta con actores de la sociedad civil en el decreto 616/2010, evidencia el espíritu participativo y democrático "basado en la integración y no en la exclusión, el multilateralismo en la región y no el unilateralismo, la tolerancia y no la xenofobia" (GIUSTINIANI, 2004, COURTIS; PACECCA, 2007; CERIANI CERNADAS, 2004).

Sin embargo, el DNU 70/2017 (ARGENTINA, 2017) produjo un viraje regresivo en políticas migratorias. La migración selectiva y diferencial, impuesta a través del citado decreto, nos recuerda las políticas emanadas de la primera ley de migraciones en Argentina, la Ley Avellaneda, y el énfasis en la seguridad y control de la Ley Videla (ARGENTINA, 1981), vigente en nuestro país por veinte ańos. El citado decreto de necesidad y urgencia -DNU- vulneró los derechos de los migrantes latinoamericanos, marcando un claro retroceso al introducir modificaciones en la actual Ley de Migraciones Nro. 25.871 (2003), modelo de ley resultado de consultas participativas democráticas.

Para analizar el cambio de dirección que introdujo el citado DNU, comenzaremos por el análisis de la ley de migraciones Nro. 25871 (ARGENTINA, 
2010b), inscripta en el paradigma de DDHH (II.1), confrontando la misma con las disposiciones emanadas del DNU 70/2017 (ARGENTINA, 2017) (II.2).

\section{II.1. La Ley de Migraciones Nro. 25.871: modelo de integración en el marco de DDHH}

A diferencias de las legislaciones anteriores, esta Ley se enmarca en el paradigma de Derechos Humanos y establece la migración en sí como un derecho humano. En palabras de Gabriel Chausovsky (2009), "el derecho a migrar, entrar, salir, trasladarse es un derecho, una atribución del ser humano que le pertenece, (...) el Estado se compromete a garantizarlo, en condiciones de igualdad y de universalidad. No hay legislación en el mundo que diga esto. Nuestra legislación cumple con lo que establece la Constitución.” Según Lila García (2017) el declarar al derecho a la migración como un derecho esencial e inalienable sobre las bases de igualdad y universalidad, es una experiencia que no encuentra correlato a nivel internacional. El migrante pasa a constituirse como sujeto de derecho (art.4) cito:

el derecho a la migración es esencial e inalienable de la persona y la República Argentina (...) garantiza sobre la base de los principios de igualdad y universalidad.", considerando al migrante "no como un sujeto sospechoso, peligroso, competidor sino como un ciudadano valioso que coopera con el desarrollo de nuestra sociedad. (GARCÍA, 2017).

De esta manera, la citada ley argentina es la primera norma a nivel mundial que efectúa este reconocimiento (NEJAMKIS, 2012), a contrapelo de las políticas de seguridad internacional, donde no existen instituciones que efectivamente velen por los derechos de migrantes y donde la restricción de la movilidad humana es moneda común de los modelos migratorios (modelo norteamericano y europeo).

A nivel latinoamericano, la actual ley de migraciones constituye una ley de avanzada al reconocer el acceso igualitario a bienes públicos y derechos sociales. Entre los derechos sociales de migrantes reconocidos por la citada ley, se destacan el derecho igualitario a servicios sociales. Cito:

[...] se asegura el acceso igualitario a las personas inmigrantes y sus familias en las mismas condiciones de protección, amparo y derechos de los que gozan los nacionales, en particular a lo referido a servicios sociales, 
bienes públicos, salud, educación, justicia, trabajo, empleo y seguridad social. De esta manera, el Estado es garante del acceso de quienes migran a sus derechos fundamentales (ARGENTINA, 2010b, art.6).

A diferencia del resto de las leyes migratorias latinoamericanas, las cuáles aplican una "visión instrumental" a la inmigración deseada de acuerdo a intereses y necesidades del país de destino, la ley de migraciones de Argentina promueve la integración regional (con base en el Acuerdo sobre Residencia ${ }^{5}$ para Nacionales de los Estados Partes del MERCOSUR, Bolivia y Chile) reconociendo a los ciudadanos de otros países vecinos como residentes temporarios con permiso de trabajo por dos ańos prorrogable. A través del Programa Patria Grande (ARGENTINA, 2010a) se hizo posible la regularización documentaria migratoria de las personas que residían en Argentina y que se encontraban invisibilizadas y excluidas del acceso a derechos; garantizando el derecho de interponer los recursos administrativos de Reconsideración, Jerárquico o Alzada, o bien recurrir directamente vía recursiva judicial. Por otra parte, se incorpora el derecho a la reunificación familiar, se enumeran las acciones que debe realizar el Estado para favorecer la integración de los migrantes y para facilitar la consulta o participación de los extranjeros en las decisiones relativas a la vida pública y a la administración de las comunidades locales donde residan.

Más allá del indiscutible avance normativo que significó en DDHH esta ley de migraciones, las críticas que se realizaron a la misma se centraron en la operatividad de esta norma, al no cumplir en muchas disposiciones con el principio general del derecho a la migración como un derecho humano (ej. pensiones por discapacidad, jubilaciones, exigencia diferencial de años entre el migrante y el ciudadano). Estas restricciones contradicen directamente los principios de igualdad, no discriminación y protección de derechos humanos que la ley expresa en su parte general. Por otra parte, la ley no reconoce las identidades de los migrantes, sus diferencias en lo que hace a la interculturalidad, omitiendo acciones para su respeto (AIZENBERG, 2011; JELIN; GRIMSON; ZAMBERLIN, 2006; FORNET BETANCOURT, 2003). La ausencia de reconocimiento a las identidades se suele traducir en discriminación y vulneración de derechos (documentación, violencia institucional, discriminación, separación de familias, no acceso a salud, educación, justicia). Los derechos vulnerados de las personas migrantes se multiplican si tenemos en cuenta el entrecruzamiento de género,

\footnotetext{
5 Disponible en: https:/www.mercosur.int/documento/acuerdo-residencia-nacionales-estados-partes-mercosurbolivia-chile/. Acceso en: 13 set. 2021.
} 
la raza/etnia, clase social, diversidad funcional y la edad (CRENSHAW, 2012; CURIEL, 2005; MARTINEZ PIZARRO; REBOIRAS-FINARD, 2010).

\section{II.2. EL giro político neoconservador del DNU 70/2017: políticas de seguridad y control}

El DNU 70/2017 (ARGENTINA, 2017) reinstauró las políticas selectivas de inmigración y profundizó las situaciones de irregularidad del migrante, con el consiguiente aumento de la vulnerabilidad social de los migrantes latinoamericanos y afrodescendientes (GARCÍA, 2017). Su imposición se centra en ideas xenófobas que llevaron a identificar al migrante con el delincuente, cito:

Que ante recientes hechos de criminalidad organizada de público y notorio conocimiento, el Estado Nacional ha enfrentado severas dificultades para concretar órdenes de expulsión dictadas contra personas de nacionalidad extranjera, como consecuencia de un complejo procedimiento recursivo que, en algunos casos, puede llegar a siete (7) ańos de tramitación. Que, a su vez, la población de personas de nacionalidad extranjera bajo custodia del servicio penitenciario federal se ha incrementado en los últimos ańos hasta alcanzar en 2016 el veintiuno coma treinta y cinco por ciento $(21,35 \%)$ de la población carcelaria total (ARGENTINA, 2017).

La falsedad del dato del que parte la formulación del DNU fue desmentida por el Informe de la Comisión Penitenciaria Argentina: la población carcelaria migrante no se ha incrementado. Por el contrario, ha permanecido estable desde hace más de 10 años. De los 2.000.000 de personas privadas de la libertad solo el 5\% son migrantes (4.400 personas). Los extranjeros detenidos en cárceles federales y provinciales son un $6 \%$ del total. Pero, sin importar los hechos, éste decreto, emanado del Poder Ejecutivo, modificó la mencionada ley de migraciones 25.871 y de nacionalidad 346 para habilitar políticas diferenciadas y selectivas, que permitan el control y la vigilancia policial del migrante, políticas que nos remontan a las viejas leyes restrictivas de migrantes en Argentina (Avellaneda y Videla), las cuáles discriminaron - históricamente- a los migrantes de países limítrofes. Esto es, la política selectiva nos remonta a nuestros orígenes nacionales y al inicio de nuestra política migratoria: la formación del Estadonación, a fines del s. XIX y principios del XX, a partir del genocidio indígena,y la primera ley inmigratoria de nuestro país ("Ley Avellaneda"), la cual tuvo por objetivo principal atraer a los migrantes blancos para contribuir a poblar todo 
el territorio argentino (CAGGIANO, 2008a, 2008b; CASARAVILLA, 2000). La citada ley Avellaneda alentaba una inmigración europea y moralmente capaz de adaptarse al país y de trabajar para su desarrollo; excluyendo a las personas provenientes de países limítrofes. La migración es una parte clave del proyecto político liberal blanco y europeizado. ${ }^{6}$ En la misma línea, la citada Ley Videla Nro. 22.439 (ARGENTINA, 1981), en su artículo 2 establece que "el Poder Ejecutivo, de acuerdo con las necesidades poblacionales de la República, promoverá la inmigración de extranjeros cuyas características culturales permitan su adecuada integración en la sociedad argentina”. En el marco de la Doctrina de Seguridad Nacional de la Dictadura, esta ley representa el poder de vigilancia, control y persecución.

El poder de policía se centraría también en la administración, a partir de: la distinción entre ilegalidad por ingreso y por permanencia; la negación de derechos sociales a los migrantes; la obligación de denuncia administrativa de los migrantes irregulares (en salud, en educación, administración, registro civil, empresas, escribanos etc.); la expulsión y prohibición de reingresar al país de manera permanente; la pena de prisión; la imposibilidad del recurso judicial, entre otros. La misma ley es conocida por su "alto carácter restrictivo y persecutorio en el tratamiento del fenómeno migratorio”, sin contar con las garantías de debido proceso (Poder judicial) al no prever la posibilidad de acceder a un recurso judicial (NEJAMKIS, 2012).

El DNU 70/2017 (ARGENTINA, 2017) rehabilitó, precisamente, los procedimientos de detención y deportación express sin proceso judicial y defensa justa. Esta detención se aplica a: -quienes hayan cometido fallas administrativas en la acreditación del trámite de ingreso; -quienes hayan resistido a la autoridad en el contexto de una marcha o una represión por venta callejera ambulante; -quienes hayan cometido delitos menores. Por lo tanto, cualquier infracción penal y contravencional puede ser causal para la expulsión del país de una persona migrante ${ }^{7}$. Claramente, tales políticas de control y seguridad poseen puntos en común con la Ley Videla, mencionada anteriormente, al criminalizar a los migrantes latinoamericanos y afrodescendientes sin garantizar una defensa justa. Su finalidad no es identificar y deportar narcotraficantes, hecho que la Ley de

\footnotetext{
6 Esta ley, en el artículo 12 definía como inmigrante a "todo extranjero jornalero, artesano, industrial, agricultor o profesor, que siendo menor de sesenta años y acreditando su moralidad y sus aptitudes, llegase a la república para establecerse en ella, en buques a vapor o a vela, pagando pasaje de segunda o tercera clase, o teniendo el viaje pagado por cuenta de la Nación, de las provincias o de las empresas particulares, protectoras de la inmigración y la colonización".

7 En la ley de migraciones (25.871) se requería un mínimo de gravedad en los delitos para que estos fueran causal de expulsión: 3 años para denegar el ingreso, 5 años y otros requisitos si se trataba de personas residentes.
} 
migraciones Nro. 25871/2003 (ARGENTINA, 2010b) contemplaba. Bajo las nuevas políticas selectivas todo migrante se encuentra en permanente estado de sospecha, persecución, control, vigilancia, represión, y posible deportación por "delincuente" sin juicio y causa justa.

El citado DNU constituye un claro retroceso en relación al paradigma de DDHH de la ley de migraciones abordada anteriormente: amplía las causas que permiten la detención y expulsión de personas migrantes en situación irregular, habilita la revisión de las radicaciones otorgadas para quienes tienen antecedentes penales o condenas (sin importar el tipo de delito o su situación procesal); modifica los trámites de expulsión para que sean inmediatas (solo le da tres días para recurrir luego de la notificación), sin control judicial ni defensa legal adecuada; elimina la unidad familiar y el arraigo como condiciones que evitan la expulsión (CELS, 2017a, 2017b).

Por otra parte, modifica la forma de acceso a la nacionalidad argentina, proponiendo que en lugar de exigir que la persona solicitante acredite más de dos años de residencia en el país, se pida una evaluación por un juez federal una vez que se demuestre que esa residencia es "legal". Esto agrava la posibilidad de regularización de la situación del migrante, ante el miedo a ser deportado y ante las dificultades tecnológicas de tramitar su residencia y/o DNI, restringiendo la posibilidad del ejercicio de la mayoría de sus derechos (económicos, políticos, sociales y culturales) y profundizando su vulnerabilidad social. La regularización se hizo cada vez más complicada a partir del nuevo sistema informático de solicitud de residencia denominado RADEX -2018- que llevó a la anulación de turnos y al otorgamiento de nuevos turnos con un ańo de demora, debido a las exigencias de cargas de internet. La brecha digital dificultó -para una gran parte de la población- el acceso a la residencia.

Por último, a pesar de que la ley de migraciones reconoce legalmente los derechos sociales de los migrantes y el citado DNU no modifica los mismos, "en los últimos años se ha documentado la negativa de hospitales y centros de salud a proveer asistencia sin DNI. Sin ir más lejos, la tarjeta alimentaria y los planes sociales tiene como requisito el DNI y la residencia" (GARCÍA et al., 2020, p.181).

En marzo del 2018 este DNU 70/2017 (ARGENTINA, 2017) fue declarado inconstitucional por la Sala V de la Cámara de lo Contencioso Administrativo Federal, en tanto restringe el acceso al debido proceso, al principio de inocencia y el derecho a un defensor público; y constituye una herramienta de impunidad para las fuerzas de seguridad al habilitar a detener y expulsar a migrantes que ejerzan el derecho a la protesta social. El DNU 70/2017 
(ARGENTINA, 2017), derogado en la actualidad (Decreto Nro. 138, 2021) ${ }^{8}$, ha sido un instrumento de control social y exclusión de las poblaciones migrantes y refugiadas provenientes de países limítrofes en su mayoría.

La aplicación de decretos de necesidad de urgencia es propia de gobiernos que buscan introducir cambios abruptos en políticas sociales sin consenso democrático ni consulta previa a la población (GARAY, 1989). En este sentido, al igual que el citado DNU 70/2017, el DNU 908/2016 impuso un nuevo giro en programas de salud, coincidiendo con los cambios de la OMS en materia de Cobertura Universal de Salud -CUS-. Este programa, lejos de ampliar el acceso a la salud, restringió el mismo excluyendo a extranjeros y migrantes; esto es, retrocediendo en el reconocimiento de un derecho humano básico, el derecho a la salud, para todos.

\section{Cambios encubiertos en políticas sanitarias: exclusión de migrantes y privatización}

Como hemos señalado al inicio del trabajo (I), a nivel internacional la Organización Mundial de la Salud (OMS, 2007) acentúa la importancia de garantizar a todos los migrantes un derecho humano básico, como lo es el derecho a la salud, considerando a la misma migración como un determinante global de la salud. El no acceso a la atención de la salud de migrantes deja a los mismos desamparados, vulnerando sus derechos. Curiosamente, en el año 2016 la OMS pasó de tener un enfoque humanitario sobre salud y migración, a esforzarse por mejorar los sistemas de salud de manera más amplia y alcanzar la supuesta cobertura sanitaria universal (en adelante CUS). En esta sección analizaremos cómo la Cobertura Universal de la Salud (DNU 908/2016, CUS) se conecta con las restricciones recientes, a nivel internacional y nacional, en la atención de la salud de migrantes; permitiendo la misma privatización del sistema de salud argentino a través de la exigencia de pagos de seguros privados para migrantes.

Pero, antes de ello, es necesario realizar algunas precisiones conceptuales sobre cómo el derecho a la salud es reconocido en nuestra constitución y en la ley de migraciones Nro. 25871/2003 (ARGENTINA, 2010b), mostrando las contradicciones que existen entre el DNU 908/2016 y la normativa argentina.

8 Disponible en: https://www.boletinoficial.gob.ar/detalleAviso/primera/241471/20210305. Acceso en: 30 set. 2021. 


\section{III.1. La ley de migraciones Nro. 25.871/2003 y el derecho a la salud de migrantes}

A nivel nacional, el sistema de salud argentino ha garantizado, constitucional e históricamente, el derecho a la salud sin exclusión. Aun en el marco de la Ley Videla de la dictadura, bajo la cual el migrante no era sujeto de derechos; la misma prevé en su art. 103 que:

las instituciones hospitalarias o asistenciales, ya sean públicas, nacionales, provinciales o municipales, o las privadas (...) deberán exigir a los extranjeros que solicitaren, o a aquellos a quienes se les prestare, asistencia o atención, que acrediten identidad y justifiquen, mediante constancia hábil su permanencia legal en la República. Cuando no los posean -sin perjuicio de su asistencia o prestación- quedarán obligados a comunicar, dentro de las veinticuatro (24) horas a la autoridad migratoria, los datos filiatorios y el domicilio de los mismos (ARGENTINA, 1981, el subrayado es nuestro).

Desde el marco de DDHH, la actual ley de migraciones establece en su art. 8:

No podrá negársele o restringírsele, en ningún caso, el acceso al derecho a la salud, la asistencia social o atención sanitaria a todos los extranjeros que lo requieran, cualquiera sea su situación migratoria. Las autoridades de los establecimientos sanitarios deberán brindar orientación y asesoramiento respecto de los trámites correspondientes a los efectos de subsanar la irregularidad migratoria (ARGENTINA, 2010b, art.8).

Al respecto, nuestra Constitución Nacional sostiene que "Los extranjeros gozan en el territorio de la Nación de todos los derechos civiles del ciudadano (...) No están obligados a admitir la ciudadanía, ni a pagar contribuciones forzosas extraordinarias." (ARGENTINA, 1994, art.20).

Resulta claro que, de acuerdo a la normativa vigente, no puede ni debe recaer bajo la responsabilidad individual del migrante el acceso a la atención de la salud, siendo ésta una responsabilidad social de los Estados y Organismos Internacionales.

Ahora bien, la claridad en la defensa del derecho igualitario a la salud (art. 8) por la ley de migraciones, no se refleja en el reconocimiento de las diferencias 
culturales que se dan en migración y salud. El Estado garantiza formalmente el acceso a la salud de migrantes, pero no permite su participación horizontal, el diálogo intercultural en el sistema de salud (BERENGUERRA, 2014), desconociendo los saberes tradicionales complementarios para el cuidado de la salud y la heterogeneidad de formas de vida. Se hace necesario avanzar en el trazado de puentes interdisciplinarios para el diálogo intercultural, con mirada de género (DI PIETRO, 2015; ESTEBAN, 2006; HARDING, 2008), y brindar signos de ruptura con un modelo colonial y patriarcal (SEGATO, 2014; LUGONES, 2014). De acuerdo a Cerruti (2010), esta falta de reconocimiento genera resistencias intra grupos que las conduce a no recurrir a la atención gratuita en los centros de salud. Asimismo, se suman actitudes discriminatorias hacia las mujeres migrantes latinoamericanas, pensadas como mestizas, pobres y desinformadas (ARGENTINA, 2012). El no reconocimiento de la justicia epistémica (SANTOS, 2017), del diálogo intercultural, recrudece las múltiples desigualdades que sufren las mujeres migrantes, profundizando la vulneración de sus derechos. La igualdad de acceso a la salud, sin la comprensión de la diversidad cultural situada (GRIMSON, 2006), es insuficiente. Como veremos seguidamente, la misma igualdad de acceso a la salud del sistema será amenazada a partir de creencias xenófobas impulsadas desde el mismo Estado en contra de los migrantes latinoamericanos (BELVEDERE et al., 2007; CAGGIANO, 2008a, 2008b), habilitando la encubierta privatización del sistema de salud argentino.

\section{III.2. ¿Qué resulta de la conjunción de la CUS y los seguros pagos para migrantes?}

Equipar la cobertura universal a la salud -CUS, DNU 908/2016- al derecho (igualitario) a la salud es erróneo. Si uno analiza las políticas que se desprenden de una y otra posición, las consecuencias no son las mismas: la CUS excluye del sistema de atención de la salud hospitalario a los migrantes, exigiéndoles el pago de un seguro privado (seguro social). El derecho a la salud, reconocido por nuestra constitución, incluye a los migrantes en el acceso igualitario a la atención de la salud sin exigir DNI.

El uso acrítico de ese concepto, CUS, lleva a confusiones no casuales; al igual que la ambigüedad del concepto de vulnerabilidad y sus usos - "empoderamiento (DDHH)" vs. "uso instrumental de vulnerabilidad (estático)"; o el uso de "Atención Primaria de la Salud" -APS- y la "Atención Primaria de la Salud Selectiva” -APS Selectiva- del Banco Mundial, entre otros. La apropiación de conceptos "progresistas" por Organismos Internacionales y por el mismo Estado, 
con fines opuestos a los creados, tiene como objetivo lograr un fin neutralizador en lo que respecta a la participación y/o reclamo de la población en el sistema sanitario (ORTÚZAR, 2016). La CUS en Argentina no se traduce en políticas a favor del acceso igualitario de migrantes, sino en credenciales electrónicas que faciliten identificar pagos (seguros privados; obras sociales -empleadores-; o seguro público estatal). El DNU 908/2016 prioriza un sistema de e-gobernanza y la creación de Credenciales electrónicas e historias clínicas electrónicas para identificar a los pacientes que poseen cobertura social -por el empleador ${ }^{9}$ o por seguro privado, de los que no poseen, como sería el caso del migrante irregular. Como he expresado en anteriores investigaciones, el objetivo de la CUS es el financiamiento y recaudación eficiente: las credenciales electrónicas permitirían identificar qué 'usuario' se encuentra financiado, reasignando el reparto de las facturaciones a las obras sociales y servicios tercerizados (ORTÚZAR, 2018). A través del cruce de la información, el "sistema" decide a quien se atiende en función de la aseguración de la recaudación y el pago. A pesar de presentarse la CUS para eliminar toda forma de discriminación en base a criterios de justicia distributiva discriminación social, económica, cultural o geográfica (Decreto 908/2016), se privilegia lo financiero por sobre los derechos humanos.

\section{Ley provincial 6116/2019 de Jujuy}

A nivel provincial, y con el amparo del gobierno nacional, se impulsa la ley 6116/2019 de Jujuy (ARGENTINA, 2019), la cual fija el "Seguro provincial de salud para personas de otros países". El proyecto sostiene que su objetivo es la protección de la salud y la no discriminación. Sin embargo, la cobertura legal limita el acceso a la salud a personas que requieren distintos tratamientos, incluso de urgencia, por el hecho de ser extranjeros o no contar con residencia definitiva. Esta ley nada dice del derecho a la salud reconocido en la CN y en la Ley de migraciones. Por el contrario, a través de un tergiversado uso de reciprocidad (que los argentinos tengan en Bolivia el mismo nivel de atención de la salud que los bolivianos tienen en Argentina), promueven el cobro de seguros sin reconocer que nuestro sistema de salud defiende la salud pública y gratuita. Esto confunde aún más el significado de la cobertura universal de salud: ¡cómo es posible defender, simultáneamente, bajo un mismo programa de emergencia

\footnotetext{
9 La particularidad del sistema de salud mixto argentino es la expansión de la oferta pública universal y gratuita de servicios de salud conjuntamente con la expansión del seguro social de los trabajadores asalariados (obra social). Entre 1947 y 1951 se sanciona las leyes de sanidad pública nro. 13.012 y de servicios 13.019, financiando los servicios públicos al $65 \%$ de la población (TOBAR, 2002).
} 
sanitaria, la cobertura universal a la salud y el pago de seguros (Sistema provincial de Seguros de Salud para Extranjeros) para migrantes? La razón es financiera: las credenciales electrónicas permitirían asentar -en bases de datos cruzadas- quiénes tienen seguros privados u obras sociales (salud a cargo del empleador) para reforzar la recaudación de fondos. En la práctica, esto equivale a dejar afuera de la atención de la salud a quien no figure en el sistema y no pueda pagar, lo cual implica la privatización encubierta del sistema de salud argentino. De acuerdo a Karasik y Yufra (2019, p.5), cito:

Los efectos sociales actuales y potenciales del accionar del Poder Ejecutivo y Legislativo son de gran alcance, al introducir un principio de discriminación y mercantilización que altera los fundamentos y el sentido de todo el sistema de salud público en la Argentina. El consenso logrado en el cobro para acceder a la salud podría ser trasladado a otros grupos sociales, siendo una puerta a la privatización de la salud y los bienes públicos.

El Proyecto de Ley de seguros provinciales de Jujuy Nro. 6.116/19 (sin reglamentar), impulsado bajo el manto de la CUS, avanza en la línea de la privatización de la salud superando en sus principios discriminatorios a la misma Ley Videla. Si examinamos su art. 4 sostiene que "la negativa o interrupción de la atención médica por parte de los agentes del servicio provincial de salud se considerará infracción grave”. Pero, al no indicar delito, la infracción podría habilitar prácticas de discriminación por los efectores de salud. Dichos efectores de salud son los mismos que permitieron generar, a través de actitudes xenófobas, los datos falsos ${ }^{10}$ sobre cómo el recorte de las prestaciones de salud a los nacionales responde a la sobrecarga del sistema de salud por extranjeros o migrantes bolivianos. Según la información provista por el Ministro de Salud, el total de pacientes atendidos en guardia y consultorios externos del Hospital Pablo Soria en el año 2017, el 96\% fueron atenciones realizadas a nacionales y sólo el 3,7\% de pacientes bolivianos/as (información que dista mucho del 30\% publicado). Sólo el 5\% de la atención médica es de extranjeros/migrantes. Siguiendo el Informe de Karasik:

\footnotetext{
${ }^{10}$ Los diversos discursos que se pusieron en juego en el debate y en la Ley dan cuenta de formas de registro de la condición extranjera y de la situación migratoria que carecen de toda validez legal y técnica. En ese marco, no pudieron ofrecer la información precisa sobre el universo al que se pretende obligar a la contratación de un seguro de salud y, por consiguiente, sobre el impacto presupuestario en el sistema de salud.
} 
[...] del total de nacidos vivos en establecimientos públicos de Jujuy durante 2016, sólo el 0,44\% tenían madres con residencia habitual fuera de nuestro pais (frente al 0,03\% nacional) y de los egresos hospitalarios sólo un 0,29\% tenian residencia habitual en el extranjero (Fundación Soberania Sanitaria, 2018). En cuanto a los tratamientos de alto costo y complejidad, cabe señalar que aún bajo la vigencia de la Ley de Migraciones existen restricciones a los extranjeros/as en ciertas prácticas de gran complejidad y alto costo (ej. Trasplantes), exigiendo la residencia permanente o temporaria según los casos. El Informe evidencia que la condición de nativo o extranjero o las categorías de residencia de los pacientes no surgen de los registros sino que son atribuidas por los efectores de salud. Esto coincide con los resultados de investigaciones propias y ajenas en Jujuy (KARASIK, 2005, p.25).

Al igual que el DNU 70/2017 (ARGENTINA, 2017), esta instancia legislativa provincial de Jujuy fue propuesta y apoyada en base a datos falsos. Lejos de preocuparse por la inequidad en salud, se buscó promover creencias xenófobas que resquebrajaban la solidaridad de los pueblos para avanzar peligrosamente sobre los bienes públicos. "Estas iniciativas legislativas de carácter socialmente disolvente, atentan contra los principios de igualdad y gratuidad de nuestro sistema de salud público y profundizan el régimen de vulnerabilidad de la población migrante" (KARASIK, YUFRA, 2019, p. 48).

\section{Conclusión general}

Hemos comenzado el recorrido de nuestro análisis, sobre los giros e intersecciones entre políticas internacionales y nacionales de migraciones, con la crítica a la definición estrecha de vulnerabilidad aplicada a migrantes, la cual apela a grupos generalizados por características fijas, no permitiendo estudiar la posibilidad de cambios, ni el desarrollo de la autodeterminación y/o el empoderamiento de éstos grupos, como sí ocurre con la definición relacional y dinámica de vulnerabilidad propuesta. Es preciso cuestionar el uso instrumental que se hace de la vulnerabilidad desde las políticas de seguridad (internacionales y nacionales), por su impacto negativo y estático en la percepción (y autopercepción) del migrante, y en el diseño de políticas públicas sobre migraciones, centradas en el control y la privatización de bienes públicos y servicios. Es necesario reconocer las relaciones institucionales asimétricas e históricas que hicieron posible el sometimiento de personas, grupos, pueblos y naciones enteras; al mismo tiempo que se asume la responsabilidad social en la protección de los migrantes. La vulnerabilidad no es 
una característica constitutiva ni estática de los migrantes, sino una característica relacional que se da entre estos grupos, Estados, y organizaciones sociales e internacionales, responsables de diseñar políticas de migraciones para proteger sus derechos humanos y empoderar a los mismos con fines de salvaguardar su dignidad e integridad.

A nivel internacional y nacional asistimos a constantes vaivenes políticos de avances y retrocesos en derechos humanos, producto de la tensión entre el paradigma de derechos humanos y el paradigma de regulación y control. El análisis de la misma nos obligó a precisar los grandes logros de la actual Ley de migraciones de Argentina, con su reconocimiento del derecho a migrar, precedente único a nivel internacional, y del derecho a la salud como derecho humano básico. El modelo de integración solidaria propuesto por dicha ley permitió la regularización de la situación migratoria de las personas de países vecinos (Programa Patria Grande, ARGENTINA, 2010a, Acuerdos en el Mercosur), accediendo a derechos sociales y disminuyendo la vulnerabilidad social de los migrantes al proteger sus derechos y empoderarlos. Sin embargo, esta ley no avanzó en el reconocimiento de la diversidad cultural situada tanto a nivel comunitario como a nivel sanitario, encontrando problemas operativos para aplicar sus principios de universalidad y no discriminación, como también para avanzar hacia el diálogo intercultural.

Asimismo, las conquistas de esta ley se vieron amenazadas a partir del DNU 70/2017 (ARGENTINA, 2017), el cual constituye un giro hacia las políticas del paradigma policial de control y seguridad (políticas vigentes en la Ley Videla de migración de la dictadura argentina), no garantizando el debido proceso judicial y favoreciendo la deportación express de migrantes. De esta manera se imponen arbitrariamente políticas selectivas y diferenciales, las cuáles nos remonta a los inicios de inmigración blanca en Argentina (Ley Avellaneda, op. cit). Este último modelo de control coincide con las políticas de "migración segura” vigentes a nivel internacional y aplicadas por los modelos de migración imperantes (Estados Unidos y Europa). Lejos de proteger efectivamente a los migrantes en situación de vulnerabilidad, el DNU 70/2017 (ARGENTINA, 2017) generó desigualdades múltiples para los migrantes latinoamericanos y afrodescendientes por derechos vulnerados. Esto es, las persecuciones y trabas que sufrieron los migrantes para regularizar su residencia obstaculizaron el acceso a sus derechos sociales (acceso a la vivienda vs. imposibilidad de alquilar; trabajo digno vs. explotación laboral, subsidios sociales vs. desamparo, acceso a la salud vs. negación del acceso a la salud por falta de DNI, entre otros). 
He aquí la paradoja de garantizar, a través de la constitución y de la ley de migraciones, los derechos sociales; pero restringirlos en la práctica, lo cual lleva a discriminar al extranjero/migrante. Lamentablemente, las creencias xenófobas que acompańaron la imposición de este decreto (migrante como delincuente) encontraron eco en la comunidad y en el ámbito legislativo provincial (Jujuy), impulsándose leyes para comercializar seguros de salud para migrantes. El modelo de integración y solidaridad de la ley de migraciones, centrado en la igualdad de acceso a derechos sociales y en la equiparación del migrante con el ciudadano, permitió promover la igualdad de acceso a derechos humanos, pero descuidó la necesaria integración de la diversidad cultural en sus diferentes campos. Amparados en creencias falsas del migrante/delincuente/usurpador, y a través de métodos antidemocráticos (DNU autoritarios), se abrió la caja de pandora, dando lugar a la comercialización de bienes públicos, ejemplificada con la privatización del sistema de salud argentino. Estos cambios en la arena de políticas migratorias en Argentina concuerdan con el giro en políticas internacionales en migraciones, pasándose del paradigma de $\mathrm{DDHH}$ hacia el paradigma regulatorio (seguridad y control).

Por último, la implementación por decreto de la CUS en nuestro país (DNU 908/2016) coincide con el cambio de posición de la Organización Mundial de la Salud. Las preocupaciones de la OMS por el derecho humanitario a la salud del migrante fueron reemplazadas por la propuesta técnica de la CUS, la cual restringe, en Argentina, el acceso a la salud del extranjero/migrante. A través del uso de conceptos progresistas (acceso universal a la salud -acceso selectivo-, atención primaria de la salud -APS selectiva-; protección del migrante vulnerable -migración selectiva-, entre otros), se encubre la misma comercialización de bienes públicos. En nombre de la seguridad, la eficiencia económica y financiera, y a través de Decretos autoritarios e injustificados avalados por campañas xenófobas basadas en datos falsos, se excluyó al migrante del sistema de salud público, promoviéndose la privatización de la salud (ARGENTINA, 2019), contraria a nuestra Constitución y a la Ley de Migraciones Nro. 25871, 8. Resulta claro que el Estado incumplió, a partir del DNU 70/2017 (ARGENTINA, 2017), los principios y derechos reconocidos en la constitución y su obligación de protección a migrantes, vulnerando sus derechos humanos, multiplicando las desigualdades, y generando una sociedad injusta, con discriminación, xenofobia y racismo.

En tiempos neoconservadores, la apertura de la puerta a la comercialización de bienes públicos -vulneración del derecho humano a la salud de los migrantes por demanda de seguros privados de salud-; pone en riesgo el mismo 
sistema público de salud como un todo, y, con él, los derechos humanos arduamente conquistados. Asumamos el reconocimiento del derecho a migrar y del derecho a la salud como derechos humanos, defendiendo la responsabilidad social de protección del derecho a la salud de migrantes en pandemia.

"Al reconocerse como vulnerables, las personas comprenden la vulnerabilidad del otro, así como la necesidad del cuidado, de la responsabilidad y de la solidaridad, y la no explotación de esa condición por parte de otros" (NEVES, 2006, p.157).

\section{REFERENCIAS}

ACNUR. Migrantes en situaciones de vulnerabilidad: Perspectiva del ACNUR. 2017. Disponible en: https://www.refworld.org/cgi-bin/texis/vtx/rwmain/opendo cpdf.pdf? reldoc=y\&docid=5979dcfa4. Acceso en: 14 set. 2021 .

AIZENBERG, L. Hacía una aproximación crítica a la salud intercultural. Revista Latinoamericana de Población, Cuernavaca, v. 5, n. 9, p. 49-69, 2011.

ALTAMIRANO RÚA, T. Refugiados ambientales: Cambio climático y migraciones. Lima: Fondo Universidad Pontificia del Perú, 2014.

ARENDT, H. Los orígenes del totalitarismo. Madrid: Taurus, 1974.

ARGENTINA. Ley Provincial n. 6116, de 2019. Creación del Sistema Provincial de Seguro de Salud para Personas Extranjeras. Erreius, Buenos Aires, 2019. Disponible en: https://www.erreius.com/Legislacion/documento/20190222091419320/ley-6116creacion-del-sistema-provincial-de-seguro-de-salud-para-personas-extranjeras. Acceso en: 14 set. 2021.

ARGENTINA. Poder Ejecutivo de la Nación. Decreto n 70/2017. Modificación de la ley $\mathrm{N}^{\circ} 25.871$. InfoLeg, Buenos Aires, 2017. Disponible en: http://servicios. infoleg.gob.ar/infolegInternet/anexos/270000-274999/271245/norma.htm. Acceso en: 3 set. 2021.

ARGENTINA. Ministerio de Justicia y Derechos Humanos. Decreto de Necesidad de Urgencia: DNU 908/2016. InfoLEG, Buenos Aires, 2016. Disponible en: http:// servicios.infoleg.gob.ar/infolegInternet/anexos/260000-264999/264047/norma.htm. Acceso en: 3 set. 2021.

ARGENTINA. Boletín de Salud Sexual y Reproductiva. Programa Nacional de Salud Sexual y Procreación Responsable. Salud Sexual, Buenos Aires, v.11, n.3, p.1-10, 2012. Disponible en: https://www.argentina.gob.ar/salud/sexual. Acceso en: 29 set. 2021. 
ARGENTINA. Ministerio del Interior. Patria Grande: Programa Nacional de Normalización Documentaria Migratoria: informe estadistico. 2010a. Disponible en: http://www.migraciones.gov.ar/pdf_varios/estadisticas/Patria_Grande.pdf. Acceso en: 14 set. 2021.

ARGENTINA. Dirección Nacional de Migraciones. Ley de Migraciones no. 25871: Decreto 616/2010. Buenos Aires, 2010b. Disponible en: http://www.migraciones. gov.ar/pdf_varios/campana_grafica/pdf/Libro_Ley_25.871.pdf. Acceso en: 14 set. 2021.

ARGENTINA. Constitución de la Nación Argentina: Parte primera. Infojus, Buenos Aires, 1994.

ARGENTINA. Ley General de Migraciones y Fomento de la Inmigración: Ley 22.439/81. Buenos Aires, 1981. Disponible en: https://www.acnur.org/fileadmin/ Documentos/BDL/2001/0121.pdf. Acceso en: 14 set. 2021.

BELVEDERE, C. et al. Racismo y discurso: una semblanza de la situación argentina. In: VAN DIJK, T. (coord.). Racismo y discurso en América Latina. Barcelona: Gedisa, 2007.

BENHABIB, S. El ser y el otro en la época contemporánea. Barcelona: Gedisa, 2006.

CAGGIANO, S. 'Que se haga cargo su país': la cultura, los Estados y el acceso a la salud de los inmigrantes bolivianos en Jujuy. In: GARCÍA VÁZQUEZ, C. (ed.). Hegemonía e interculturalidad: Poblaciones originarias e inmigrantes. Buenos Aires: Prometeo, 2008a. p. 243-279.

CAGGIANO, S. Racismo, fundamentalismo cultural y restricción de la ciudadanía: formas de regulación social frente a inmigrantes en Argentina. In: NOVICK, S. (comp.). Las migraciones en América Latina. Buenos Aires: Catálogos, 2008b. p.31-52.

CASARAVILlA, D. ¿Ángeles, demonios o chivos expiatorios?: El futuro de los inmigrantes latinoamericanos en Argentina. In: CLACSO. Informe final del concurso: Democracia, derechos sociales y equidad; y Estado, política y conflictos sociales. Buenos Aires: CLACSO, 2000. Disponible en: http://bibliotecavirtual. clacso.org.ar/ar/libros/becas/1999/casara.pdf. Acceso en: 13 set. 2021.

CENTRO DE ESTUDIOS LEGALES Y SOCIALES [CELS]. La ONU insiste en la necesidad de derogar el DNU de migrantes. 2017a. Disponible en: https:// www.cels.org.ar/web/2017/06/la-onu-insiste-en-la-necesidad-de-derogar-el-dnu-demigrantes/. Acceso en: 14 set. 2021. 
CENTRO DE ESTUdiOS LEGALES Y SOCIALES [CELS]. Migrantes en jaque: una reforma migratoria fuera de la ley. Buenos Aires: CELS, 2017b. Disponible en: https://www.cels.org.ar/web/2017/01/migrantes-en-jaque-una-reforma-migratoriafuera-de-la-ley/. Acceso en: 3 set. 2021.

CERIANI CERNADAS, P. Nueva ley: un paso hacia una concepción distinta de la migración. In: GIUSTINIANI, R. Migración: Un derecho humano. Buenos Aires: Prometeo, 2004. p.113-135.

CHAUSOVSKY, G. Irregulares e ilegales. Ningún ser humano es ilegal, 2009. Disponible en: http://ningunserhumanoesilegal.blogspot.com.ar/2009/09. Acceso en: 13 set. 2021.

COURTIS, C.; PACECCA, M. I. Migración y derechos humanos: una aproximación crítica al "nuevo paradigma" para el tratamiento de la cuestión migratoria en Argentina. Revista Jurídica de Buenos Aires, Buenos Aires, p.183-200, 2007.

CRENSHAW, K. Cartografiando los márgenes: Intersecionalidad, políticas identitarias, y violencia contra las mujeres de color. In: PLATERO, R. (ed.). Intersecciones: cuerpos y sexualidades en la encrucijada. Barcelona: Bellaterra, S.L, 2012. (Temas contemporáneos. Serie General Universitaria) p.130.

CURIEL, O. Identidades Esencialistas o Construcción de Identidades Políticas: El dilema de las feministas afrodescendientes. In: CANDELARIO, G. E. B. (comp.). Miradas Desencadenantes: Los Estudios de Género en la República Dominicana al inicio del tercer Milenio. Santo Domingo: INTEC, 2005. p.1-17.

DI PIETRO, P. Género(s) y políticas interculturales en las Américas Latinas. 2015. Disponible en: http://prigepp.org/emails/2019/docs/info_programa_esp_GyPC.pdf. Acceso en: 13 set. 2021.

ESTEBAN, M. L. El Estudio de la Salud y el Género: Las Ventajas de un Enfoque Antropológico y Feminista. Salud Colectiva, Buenos Aires, v. 2, n. 1, p. 9-20, 2006.

FILGUEIRA, C. Estructura de oportunidades y vulnerabilidad social: aproximaciones conceptuales recientes. In: SEMINÁRIO INTERNACIONAL: LAS DIFERENTES EXPRESIONES DE LA VULNERABILIDAD SOCIAL, Santiago de Chile, 2001. Anales [...], Santiago de Chile: Naciones Unidas, 20-21 jun. 2001. Disponible en: https://docplayer.es/34581522-Estructura-de-oportunidades-y-vulnerabilidad-socialaproximaciones-conceptuales-recientes-carlos-h-filgueira-ciesu-2001.html. Acceso en: 13 set. 2021.

FORNET BETANCOURT, R. Interculturalidad: Asignatura pendiente de la filosofía latinoamericana. Erasmus: Revista para el diálogo intercultural, Buenos Aires, v.5, n.1-2, 2003. 
FREIRE, P.; FREIRE, N. Pedadogia da solidariedade. São Paulo: Paz e Terra, 2014. GARAY, A. Derechos civiles de los extranjeros y presunción de inconstitucionalidad de las normas. Buenos Aires: La Ley, 1989.

GARCÍA, L. Decreto 70/2017, Ley de Migraciones y Poder Judicial”, Rubinzal Culzoni Doctrina 230/2017, 9 de marzo de 2017.

GARCÍA, L. et al. Mujeres trans migrantes y trabajo sexual en la ciudad de Mar del Plata: Apuntes de una experiencia en el contexto del ASPO (2020). In: NICOLAO, J. (comp.). Migración regional, política migratoria y derechos sociales en el interior de la Provincia de Buenos Aires. Tandil: CEIPIL, 2020. p.181-190.

GELLI, M. A. Constitución de la Nación Argentina: Comentada y Concordada. 3. ed. actual. Buenos Aires: La Ley, 2005.

GIUSTINIANI, R. Migración: un derecho humano: Ley de Migraciones 25.871 . Buenos Aires: Prometeo Libros, 2004.

GOODIN, R. Protecting the vulnerable. Chicago: University Chicago Press, 1985.

GRIMSON, A. Nuevas xenofobias, nuevas políticas étnicas en la Argentina. In: JELIN, E.; GRIMSON, A. (comp.). Migraciones regionales hacia la Argentina: Diferencia, desigualdad y derechos. Buenos Aires: Prometeo, 2006.

HARDING, S. Sciences from Below: Feminisms, Postcolonialities, and Modernities. Durham: Duke University Press, 2008.

JELIN, E.; GRIMSON, A.; ZAMBERLIN, N. ¿¿Servicio?, ¿Derecho?, ¿Amenaza?: La llegada de inmigrantes de países limítrofes a los servicios públicos de salud. In: JELIN, E. (dir.). Salud y migración regional: Ciudadanía, discriminación y comunicación intercultural. Buenos Aires: Instituto de Desarrollo Económico y Social (IDES), 2006.

KARASIK, G. A. Etnicidad, cultura y clases sociales: Procesos de formación histórica de la conciencia colectiva en Jujuy, 1970-2003. 2005. Tesis (Doctorado en Historia) - UNT, San Miguel de Tucumán, 2005.

KARASIK, G.; YUFRA, L. Extranjería y acotamiento del derecho a la salud en una provincia de frontera: iniciativas legislativas y debates sociales en Jujuy. San Salvador de Jujuy: Tiraxi Ediciones, 2019.

KAZTMAN, R. Activos y estructuras de oportunidades: estudios sobre las raíces de la vulnerabilidad social en Uruguay. Montevideo: CEPAL, 1999. Disponible en: https://repositorio.cepal.org/bitstream/handle/11362/28651/LCmvdR180_es.pdf? sequence=1\&isAllowed=y. Acceso en: 13 set. 2021. 
KOTTOW, M. Vulnerabilidad y protección. In: TEALDI, J. C. (dir.). Diccionario latinoamericano de bioética. Bogotá: Unesco, 2008. p. 340-342.

LUGONES, M. Colonialidad y Género. In: ESPINOSA MIÑOSO, Y.; GÓMEZ CORRAL, D.; OCHOA MUNOZZ, K. (comp.). Tejiendo de otro modo: Feminismo, epistemología y apuestas descoloniales en Abya Yala. Colombia: Universidad del Cauca, 2014. p.57-74

MARTÍNEZ PIZARRO, J.; REBOIRAS-FINARD, L. Migración, derechos humanos y salud sexual y reproductiva: delicada ecuación en las fronteras. Papeles de población, Toluca, v.16, n. 64, p. 9-29, 2010.

MIGNOLO, W. Introducción. In: MIGNOLO, W. (comp.). Capitalismo y geopolítica del conocimiento: El eurocentrismo y la filosofía de la liberación en el debate intelectual contemporáneo. Buenos Aires: Ediciones del signo, 2007. p.1-53. (Colección Plural/2).

MORZILLI, M.; LEMMI, S. Contra la herencia: Vulnerabilidad social, políticas públicas y educación secundaria en jóvenes migrantes bolivianos hortícolas. In: NICOLAO, J. (comp.). Migración regional, política migratoria y derechos sociales en el interior de la Provincia de Buenos Aires. Tandil: CEIPIL, 2020. p. $162-180$

NEJAMKIS, L. Políticas migratorias en tiempos kirchneristas (2003-2010): ¿un cambio de paradigma?. In: NOVICK, S. (dir.). Migración y políticas públicas, nuevos escenarios y desafíos. Buenos Aires: Catálogos, 2012. p.89-116.

NEVES, M. P. Article 8: respect de la vulnérabilité humaine et de l'intégrité personnelle. In: UNESCO. La déclaration universelle sur la bioéthique et les droits de l'homme: histoire, principes et application. Paris: Unesco, 2009. p. 167-177.

NEVES, M. P. Sentidos da vulnerabilidade: característica, condição, princípio. Revista Brasileira de Bioética, Brasília, v.2, n.2, p.157-72, 2006.

O’NEILL, O. Towards Justice and Virtue. Cambridge: Cambridge University Press, 1996.

ONU MIGRACIÓN [OIM]. Términos fundamentales sobre migración. Disponible en: https://www.iom.int/es/terminos-fundamentales-sobre-migracion. Acceso en: 14 set. 2021.

ORGANIZACIÓN MUNDIAL DE LA SALUD [OMS]. Salud de los migrantes: Informe de la Secretaría. Consejo Ejecutivo EB122/11, 122a reunión. 20 dic. 2007. Disponible en: https://apps.who.int/gb/ebwha/pdf_files/EB122/B122_11-sp.pdf. Acceso en: 14 set. 2021. 
ORTÚZAR, M. G. Cobertura universal de salud vs. Derecho a la salud: Un análisis ético y político sobre lo universal en salud en tiempos de restauración conservadora. REvIISe: Revista de Ciencias Sociales y Humanas, San Juan, v.12, n.12, p.103-116, 2018.

ORTÚZAR, M. G. Responsabilidad social vs. Responsabilidad individual en salud. Revista de Bioética y Derecho, Barcelona, n.36, p.23-36, 2016.

QUIJANO, A. Colonialidad del poder, eurocéntrismo y América Latina. In: LANDER, E. (comp.). La colonialidad del saber: eurocéntrismo y ciencias sociales: Perspectivas Latinoamericanas. Buenos Aires: CLACSO, 2005. p. 201-246.

QUIJANO, A. Colonialidad del Poder y Clasificación Social. Journal of World Systems Research, San Francisco, v.6, n.2, p. 342-386, 2000.

SANTOS, B. de S. Justicia entre saberes: Epistemologías del Sur contra el epistemicidio. Madrid: Morata, 2017.

SCHRAM, F. R. A saúde é um direito ou um dever?: Autocrítica da saúde pública. Revista Brasileira de Bioética, Brasília, v.2, n.2, p.187-200, 2006.

SEGATO, R. Colonialidad y patriarcado moderno: expansión del frente estatal, modernización, y la vida de las mujeres. In: ESPINOSA MIÑOSO, Y.; GÓMEZ CORRAL, D.; OCHOA MUÑOZ, K. (comp.). Tejiendo de otro modo: Feminismo, epistemología y apuestas descoloniales en Abya Yala. Colombia: Universidad del Cauca, 2014. p.75-90.

TOBAR, F. Breve historia de la prestación de servicios de salud en Argentina y Políticas de Salud. In: GARAY, O. (comp.). Responsabilidad profesional de los médicos. Buenos Aires: La Ley, 2002. p.1-19

UN HUMAN RIGHTS COUNCIL. Principles and practical guidance on the protection of the human rights of migrants in vulnerable situations. 24 Feb. 2017. Disponible en: https://www.refworld.org/docid/58b010f34.html. Acceso en: 14 set. 2021.

VULNERABLE. In: REAL ACADEMIA ESPAÑOLA. Diccionario de la lengua espańola. 2019. Disponible en: https://dle.rae.es/vulnerable. Acceso en: 13 set. 2021.

Recebido em: 31 de agosto de 2020

Aprovado em: 23 de novembro de 2020 